\title{
The role of physical activity in the prevention of breast cancer: potential mechanisms of action
}

\author{
DOI: https://doi.org/10.5114/pq.2020.99752
}

Aneta Łomnicka, Iwona Malicka

Faculty of Physiotherapy, University School of Physical Education in Wrocław, Wrocław, Poland

\begin{abstract}
Breast cancer is the most prevalent malignancy in women both in Poland and worldwide. It is currently one of the largest epidemiological problems. The health-promoting lifestyle, including physical activity, plays an important role in the primary and secondary prevention of breast cancer. Studies have confirmed the relationship between regular exercise and the risk of developing breast cancer, as well as its course and prognosis. A number of possible mechanisms are involved in linking physical activity with the risk of breast cancer. Nevertheless, they have not been fully elucidated. The most important mechanisms include the impact of physical activity on the immune system, inflammatory processes, sex hormone levels, obesity, metabolic syndrome, and lifestyle. The paper attempts to discuss these mechanisms.

Key words: breast cancer, primary prevention, secondary prevention, physical activity
\end{abstract}

\section{Introduction}

During the $20^{\text {th }}$ century, a considerable lifestyle change was observed. The involvement of muscles during daily activities decreased by $80 \%$, with an increase in the pace of life [1]. Modern women are often characterized by low physical activity, high stress levels, poor nutrition, smoking, alcohol consumption, late motherhood or childlessness. At the same time, these factors are considered significant for the risk of breast cancer. Approximately $95 \%$ of all breast cancer cases are associated with lifestyle factors [2, 3].

Breast cancer is the most prevalent malignancy in women both in Poland and worldwide. It is currently one of the largest epidemiological problems. Over 1.5 million new cases are diagnosed annually worldwide, with the highest incidence rate in high-income countries [4]. Poland is among the countries with the average incidence of breast cancer. However, an increasing trend has been recently reported. Over a 2-fold increase in the incidence of this cancer has been observed since the 1990s [5]. In addition, considering the demographic changes in the Polish population and the fact that $80 \%$ of all breast cancer patients are diagnosed after 50 years of age, a further increase in the number of cases can be expected [6].

Physical activity is one of the main elements of a healthy lifestyle and plays a crucial role in health promotion. If it is maintained at an appropriate level, it constitutes a preventive measure, reducing the risk of developing diseases of affluence, including cancer [7]. The lack of physical activity is considered a cause of health loss [8]. When physical activity is analysed in the context of cancer diseases, its importance in both primary and secondary prevention should be stressed.

Increased physical activity reduces the risk of breast cancer in active women by 30-40\% [9, 10]. In addition, the onset of physical activity and its intensity are also significant, which is in line with most experimental [11-15] and epidemiological studies [16-18].
Regular physical activity in childhood and young age results in a decreased risk of breast cancer in adulthood [19, 20]. This relationship was reported by Frisch et al. [17] as early as in 1985. They demonstrated a significantly lower incidence of breast cancer among former American college athletes compared with non-athletes.

The American Cancer Society developed guidelines for the level of physical activity in cancer prevention. The Society recommended 150 minutes of moderate-intensity or 75 minutes of vigorous-intensity activity each week [21]. Donnelly et al. showed a lower risk of invasive and preinvasive breast cancer in women who were physically active for 5 or more hours per week [22]. Bernstein et al. [23] and McTiernan et al. [24] indicated the intensity level of physical activity. Bernstein et al. [23] indicated that a $20 \%$ decrease in the risk of breast cancer was found in active women who undertook 60-minute physical activity with the intensity over 6.7 metabolic equivalents at least once per week for 1 year [23]. In turn, McTiernan et al. [24] noted a 14\% decrease in the risk of breast cancer in women who at the age of 35 performed vigorous physical activity 3 times per week.

The benefits of physical activity are also observed in secondary prevention among women who undergo cancer treatment and in those who completed such therapy. A significant improvement in the circulatory and respiratory systems is reported. Additionally, physical activity reduces fatigue and improves the quality of life [25-28]. Women with a high level of physical activity and capacity are also characterized by a $50 \%$ lower relative risk of premature death compared with individuals with a sedentary lifestyle [29-31].

Summarizing, physical activity has a multidirectional effect on the human body. A number of possible mechanisms are involved in linking physical activity with the risk of breast cancer. Nevertheless, they have not been fully elucidated $[32,33]$. The most important mechanisms include the impact of physical activity on the immune system, inflammatory pro-

Correspondence address: Aneta Łomnicka, Faculty of Physiotherapy, University School of Physical Education in Wrocław, al. I.J. Paderewskiego 35, 51-612 Wrocław, Poland, e-mail: aneta.lomnicka@onet.pl

Received: 26.06 .2020

Accepted: 04.09.2020

Citation: Łomnicka A, Malicka I. The role of physical activity in the prevention of breast cancer: potential mechanisms of action. Physiother Quart. 2021;29(1):35-39; doi: https://doi.org/10.5114/pq.2020.99752. 
cesses, sex hormone levels, obesity, metabolic syndrome, and lifestyle [34].

\section{Immune system}

The activation of immune processes is due to regular physical exercise that increases the activity of the immune system [1]. Physical activity generates the release of cortisol and catecholamines, which results in an increase in the number of some cells of the immune system and changes in the humoral system. The number of natural killer (NK) cells and cytotoxic T lymphocytes can be significantly increased after physical activity (150-300\% and $50-100 \%$ in the case of NK and T cells, respectively) [35]. Both NK and T cells are the lymphocytes which constitute the first line of defence against pathogens and cells that have undergone malignant transformation. Experimental studies on mice related to breast cancer showed that weakening of the immune system and dissemination of cancer occurred after exogenous oestrogens administration, whereas training on a treadmill for 8 weeks resulted in a reduction in the tumour size, as well as an increase in NK cell and macrophage activity [36-38].

\section{Inflammatory processes}

Permanently elevated C-reactive protein (CRP) concentration is an indicator of chronic inflammation. When inflammatory factors are present in the tumour microenvironment, they facilitate the proliferation and migration of cancer cells and angiogenesis. Elevated CRP levels have been shown to increase the risk of lung, kidney, colorectal, and skin cancer in healthy individuals [39]. At diagnosis, elevated CRP in women with breast cancer was associated with decreased overall survival [40]. The Mediterranean diet and physical activity have been proven to reduce the CRP concentration. It was found that concentrations of proinflammatory cytokines, including CRP, tumour necrosis factor-alpha (TNF- $\alpha$ ), and interleukin (IL)-6, were decreased as a result of moderate physical activity [34].

Adiponectin, which was first described in 1995, is one of the many cytokines associated with inflammatory processes. Adipocytes produce adiponectin, whose concentration depends on the amount of adipose tissue. An increase in the concentration of this cytokine occurs when the amount of the tissue decreases. Additionally, adiponectin is responsible for anti-inflammatory and antimitotic activity, as well as inhibition of angiogenesis and proliferation in breast cancer cell lines [41]. Physical activity indirectly affects high levels of adiponectin. TNF- $\alpha$ and IL- 6 regulate gene expression and adiponectin secretion by adipose cells.

Reduction in adipose tissue results in a decrease in TNF- $\alpha$ and IL-6 concentrations, which leads to an increase in adiponectin [42]. Long-term and regular physical activity may cause a decrease in TNF- $\alpha$ and IL- 6 concentrations, irrespective of a decrease in adipose tissue. However, this mechanism has not been completely understood.

Regular and moderate physical activity contributes to the normalization of the balance between pro-inflammatory and anti-inflammatory cytokines [34]. Temporary exacerbation of inflammatory processes can be caused by excessive physical activity [33].

\section{Sex hormones}

A decrease in the concentrations of sex hormones and beneficial effects of physical activity, lowering the risk of breast cancer development [43]. Oestrogens promote cell growth in the breast and also stimulate proliferation [44]. Reduced exposure to oestrogen can be obtained by undertaking physical activity at a young age, which may delay the age of menarche (the later the menarche, the lower the risk of breast cancer) [2, 45]. In premenopausal women, physical activity may reduce the number of ovulation cycles, lowering long-term exposure to endogenous oestrogens and reducing the risk of breast cancer [46-48]. In postmenopausal women, physical activity can affect the levels of endogenous oestrogens by reducing adipose tissue. In obese individuals, fat tissue is a significant source of estrone and oestradiol [48-50]. By reducing the adipose tissue and increasing the level of SHBG, physical activity can also result in a decrease in the testosterone level. However, study results are inconclusive [51].

\section{Obesity and metabolic syndrome}

In recent years, overweight has become an important epidemiological problem in high-income countries [52]. Both obesity and metabolic syndrome significantly increase the risk of many different types of malignancies, including colorectal, gallbladder, breast, endometrial, ovarian, prostate, and thyroid cancer. High body mass index considerably affects the development of breast cancer. Studies show a higher risk of breast cancer in obese women compared with those who are slim [53, 54].

It is known that obese women have elevated concentrations of oestrogens that are produced by the ovaries during the reproductive period. However, in the postmenopausal period, they are produced by adipose tissue (an organ of endocrine secretion). A higher risk of carcinogenesis in the breast is reported due to prolonged exposure to oestrogen activity. Metabolic disorders are among the sequelae of abnormal secretion of sex hormones, insulin-like growth factor (IGF), leptin, angiotensin, and adiponectin. These substances are secreted by adipocytes [52]. Rosato et al. [55] indicated that overweight women were more commonly affected by metabolic syndrome, which contributes to breast cancer development, particularly in postmenopausal age.

Of note, regular physical activity can reduce obesity. Hyperinsulinemia reduces SHBG and increases the bioavailability of carcinogenic sex hormones; insulin has mitogenic and synergistic effects with oestrogens in breast cancer cell lines. As a result of physical activity, tissue sensitivity to insulin can be increased, and hence the probability of type 2 diabetes becomes reduced [56]. A meta-analysis demonstrated that women with type 2 diabetes had a 16\% higher risk of breast cancer [57]. Physical activity initiates adipose tissue reduction, muscle mass increase, and glucose transport to muscles, which protects against hyperinsulinemia and insulin resistance, associated with a decreased adiponectin concentration and excessive production of IL-6, TNF- $\alpha$, and leptin [56]. In a study on a group of 50 female mice, it was concluded that training caused changes in IGF-1 and corticosterone, which is a mechanism supporting glucose homeostasis in response to increasing energy expenditure associated with movement [58].

\section{Diet}

Physical activity can indirectly influence good health-promoting behaviours, such as a proper diet, reduction or total elimination of alcohol consumption, complete or partial smok- 
ing cessation. It is estimated that lifestyle modification can reduce the incidence of breast cancer by $50 \%$ [59].

A proper diet based on limiting the caloric content and reducing the amount of fats and cholesterol has a positive effect on a decrease in oestrogens serum concentrations [60]. Products that contain trans fatty acids should be avoided as they contribute to inflammation [61]. Fruit and vegetables are recommended (especially those with a high content of folic acid, antioxidants, and bioactive compounds) in primary and secondary breast cancer prevention. Carotenoids are proven to have a positive impact on reducing the risk of breast cancer [62].

A 1.5-fold higher risk of breast cancer is associated with daily alcohol overuse [63]. Ethanol has a considerable effect on the endocrine system. Ethanol and oestrogens are metabolized by the liver. Excessive alcohol consumption results in hepatocyte damage, which leads to abnormal metabolism of oestrogens, and their elevated concentrations contribute to a carcinogenic effect [64].

Acetaldehyde also influences the development of cancer cells by damaging the DNA and causing the destruction of folates. The deficiency of vitamins and macro- and micronutrients in the body increases the risk of developing the disease as a result of excessive alcohol consumption [65].

\section{Limitations}

Owing to the heterogeneity of the results in the literature review, it is necessary to conduct further research in the field of both primary and secondary prevention of breast cancer. The mechanisms that would fully explain the correlation between physical activity and breast cancer risk and course have not been fully discovered yet. This article presents only the most important and the most comprehensively studied ones.

\section{Conclusions}

Physical activity is considered to be a modifiable risk factor for the development and course of breast cancer. The most important are both the time of taking up physical activity (it is recommended to introduce an active lifestyle from an early age) and its intensity (which should be at least moderate).

The essential mechanisms include the influence of physical activity on the immune system, inflammatory processes, sex hormones concentration, obesity and metabolic syndrome, as well as lifestyle; however, they still need to be discussed in more detail.

\section{Ethical approval}

The conducted research is not related to either human or animal use.

\section{Disclosure statement}

No author has any financial interest or received any financial benefit from this research.

\section{Conflict of interest}

The authors state no conflict of interest.

\section{References}

1. Woźniewski M. Physical culture in the lives of people with malignant cancer [in Polish]. Adv Clin Exp Med. 2002;11(1 Suppl. 1):103-108.

2. Janssens JP, Vandeloo M. Breast cancer: a life-time disease direct and indirect age-related lifestyle risk factors [in Polish]. J Oncol. 2009;59(3):159-167.
3. Jassem J, Krzakowski M. Breast cancer [in Polish]. Oncol Clin Pract. 2018;14(4):171-215; doi: 10.5603/OCP.2018. 0027.

4. Momenimovahed Z, Salehiniya H. Epidemiological characteristics of and risk factors for breast cancer in the world. Breast Cancer. 2019;11:151-164; doi: 10.2147/ BCTT.S176070.

5. Wojciechowska U, Didkowska J, Michałek I, Olasek P, Ciuba A. Cancer in Poland in 2018 [in Polish]. Warszawa: Polish National Cancer Registry; 2020. Available from: http://onkologia.org.pl/wp-content/uploads/Nowotwory_2018.pdf.

6. Didkowska J, Wojciechowska U. Breast cancer in Poland and Europe - population and statistics [in Polish]. J Oncol. 2013;63(2):111-118.

7. Kubińska Z, Zaworski K, Mysula I, Pocztarska-Głos A. Physical activity in primary and secondary physioprophylaxis. Health Prob Civil. 2020;14(1):34-42; doi: 10.5114/hpc.2020.92522.

8. Cleland V, Granados A, Crawford D, Winzenberg T, Ball K. Effectiveness of interventions to promote physical activity among socioeconomically disadvantaged women: a systematic review and meta-analysis. Obes Rev. 2013; 14(3):197-212; doi: 10.1111/j.1467-789X.2012.01058.x.

9. Friedenreich CM, Orenstein MR. Physical activity and cancer prevention: etiologic evidence and biological mechanisms. J Nutr. 2002;132(11 Suppl.):3456S-3464S; doi: 10.1093/jn/132.11.3456S.

10. Ransdell L, Pelichkoff LM. Ensuring the health of active and athletic girls and women. National Association for Girls and Women in Sport; 2005.

11. Wang M, Yu B, Westerlind K, Strange R, Khan G, Patil D, et al. Prepubertal physical activity up-regulates estrogen receptor beta, BRCA1 and p53 mRNA expression in the rat mammary gland. Breast Cancer Res Treat. 2009; 115(1):213-220; doi: 10.1007/s10549-008-0062-x.

12. Westerlind KC, McCarty HL, Schultheiss PC, Story R, Reed $\mathrm{AH}$, Baier ML, et al. Moderate exercise training slows mammary tumour growth in adolescent rats. Eur J Cancer Prev. 2003;12(4):281-287; doi: 10.1097/0000 8469-200308000-00007.

13. Whittal KS, Parkhouse WS. Exercise during adolescence and its effects on mammary gland development, proliferation, and nitrosomethylurea (NMU) induced tumorigenesis in rats. Breast Cancer Res Treat. 1996;37(1): 21-27; doi: 10.1007/BF01806628.

14. Thompson HJ. Effect of exercise intensity and duration on the induction of mammary carcinogenesis. Cancer Res. 1994;54(Suppl. 7):1960s-1963s.

15. Malicka I, Siewierska K, Pula B, Kobierzycki C, Haus D, Paslawska $U$, et al. The effect of physical training on the $\mathrm{N}$-methyl-N-nitrosourea-induced mammary carcinogenesis of Sprague-Dawley rats. Exp Biol Med. 2015; 240(11):1408-1415; doi: 10.1177/1535370215587532.

16. Verloop J, Rookus MA, van der Kooy K, van Leeuwen FE. Physical activity and breast cancer risk in women aged 20-54 years. J Natl Cancer Inst. 2000;92(2):128135; doi: 10.1093/jnci/92.2.128.

17. Frisch RE, Wyshak G, Albright NL, Albright TE, Schiff I, Jones KP, et al. Lower prevalence of breast cancer and cancers of the reproductive system among former college athletes compared to non-athletes. Br J Cancer. 1985;52(6):885-891; doi: 10.1038/bjc.1985.273.

18. Mittendorf R, Longnecker MP, Newcomb PA, Dietz AT, Greenberg ER, Bogdan GF, et al. Strenuous physical activity in young adulthood and risk of breast cancer (United 
States). Cancer Causes Control. 1995;6(4):347-353; doi: 10.1007/BF00051410.

19. Szkiela M, Worach-Kardas H, Marcinkowski JT. Breast cancer - epidemiology, risk factors, importance of primary and secondary prevention [in Polish]. Probl Hig Epidemiol. 2014;95(2):292-302.

20. Kruk J. Self-reported physical activity and the risk of breast cancer [in Polish]. J Oncol. 2007;57(6):677-684.

21. Kushi LH, Doyle C, McCullough M, Rock CL, DemarkWahnefried W, Bandera EV, et al. American Cancer Society guidelines on nutrition and physical activity cancer prevention: reducing the risk of cancer with healthy food choices and physical activity. CA Cancer J Clin. 2012;62(1):30-67; doi: 10.3322/caac.20140.

22. Donnelly CM, Blaney JM, Lowe-Strong A, Rankin JP, Campbell A, McCrum-Gardner E, et al. A randomised controlled trial testing the feasibility and efficacy of a physical activity behavioural change intervention in managing fatigue with gynaecological cancer survivors. Gynecol Oncol. 2011;122(3):618-624; doi: 10.1016/j.ygyno. 2011.05.029.

23. Bernstein L, Patel AV, Ursin G, Sullivan-Halley J, Press MF, Deapen D, et al. Lifetime recreational exercise activity and breast cancer risk among black women and white women. J Natl Cancer Inst. 2005;97(22):1671-1679; doi: 10.1093/jnci/dji374.

24. McTiernan A, Kooperberg C, White E, Wilcox S, Coates R, Adams-Cambell LL, et al. Recreational physical activity and the risk of breast cancer in postmenopausal women: the Women's Health Initiative cohort study. JAMA. 2003; 290(10):1331-1336; doi: 10.1001/jama.290.10.1331.

25. Schmitz KH, Courneya KS, Matthews C, Demark-Wahnefried W, Galvão DA, Pinto BM, et al. American College of Sports Medicine roundtable on exercise guidelines for cancer survivors. Med Sci Sports Exerc. 2010;42(7): 1409-1426; doi: 10.1249/MSS.0b013e3181e0c112.

26. Rock CL, Doyle C, Demark-Wahnefried W, Meyerhardt J, Courneya KS, Schwartz AL, et al. Nutrition and physical activity guidelines for cancer survivors. CA Cancer J Clin. 2012;62(4):243-274; doi: 10.3322/caac.21142.

27. Mayor S. Chronic and late effects: how physical activity can help. CancerWorld. 2013;54:39-44.

28. Odynets T, Briskin Y, Zakharina I, Yefremova A. Influence of a water physical rehabilitation program on the hemodynamic parameters in breast cancer survivors. Physiother Quart. 2019;27(2):6-10; doi: 10.5114/pq. 2019.84267.

29. Irwin ML, Smith AW, McTiernan A, Ballard-Barbash R, Cronin K, Gilliland FD, et al. Influence of pre- and postdiagnosis physical activity on mortality in breast cancer survivors: the health, eating, activity, and lifestyle study. J Clin Oncol. 2008;26(24):3958-3964; doi: 10.1200/JCO. 2007.15.9822.

30. Holick CN, Newcomb PA, Trentham-Dietz A, Titus-Ernstoff L, Bersch AJ, Stampfer MJ, et al. Physical activity and survival after diagnosis of invasive breast cancer. Cancer Epidemiol Biomarkers Prev. 2008;17(2):379386; doi: 10.1158/1055-9965.EPI-07-0771.

31. Ruiz-Casado A, Alejo LB, Santos-Lozano A, Soria A, Ortega MJ, Pagola I, et al. Validity of the physical activity questionnaires IPAQ-SF and GPAQ for cancer survivors: insights from a Spanish cohort. Int J Sports Med. 2016;37(12):979-985; doi: 10.1055/s-0042-103967.

32. McTiernan A. Mechanisms linking physical activity with cancer. Nat Rev Cancer. 2008;8(3):205-211; doi: 10.1038/ nrc2325.
33. Neilson HK, Friedenreich CM, Brockton NT, Millikan RC. Physical activity and postmenopausal breast cancer: proposed biologic mechanisms and areas for future research. Cancer Epidemiol Biomarkers Prev. 2009;18(1): 11-27; doi: 10.1158/1055-9965.EPI-08-0756.

34. Litwiniuk M, Kara I. Physical activity and cancer [in Polish]. OncoReview. 2012;2(4):228-233.

35. Nieman DC. Exercise, upper respiratory tract infection, and the immune system. Med Sci Sports Exerc. 1994; 26(2):128-139; doi: 10.1249/00005768-19940200000002.

36. Pedersen BK, Hoffman-Goetz L. Exercise and the immune system: regulation, integration, and adaptation. Physiol Rev. 2000;80(3):1055-1081; doi: 10.1152/ physrev.2000.80.3.1055.

37. MacNeil B, Hoffman-Goetz L. Chronic exercise enhances in vivo and in vitro cytotoxic mechanisms of natural immunity in mice. J Appl Physiol. 1993;74(1):388-395; doi: 10.1152/jappl.1993.74.1.388.

38. MacNeil B, Hoffman-Goetz L. Exercise training and tumor metastasis in mice: influence of time of exercise onset. Anticancer Res. 1993;13(6A):2085-2088.

39. Allin KH, Nordestgaard BG. Elevated C-reactive protein in the diagnosis, prognosis, and cause of cancer. Crit Rev Clin Lab Sci. 2011;48(4):155-170; doi: 10.3109/10408 363.2011.599831.

40. Pierce BL, Ballard-Barbash R, Bernstein L, Baumgartner RN, Neuhouser ML, Wener MH, et al. Elevated biomarkers of inflammation are associated with reduced survival among breast cancer patients. J Clin Oncol. 2009;27(21):3437-3444; doi: 10.1200/JCO.2008.18.9068.

41. Arditi JD, Venihaki M, Karalis KP, Chrousos GP. Antiproliferative effect of adiponectin on MCF7 breast cancer cells: a potential hormonal link between obesity and cancer. Horm Metab Res. 2007;39(1):9-13; doi: 10.1055/ s-2007-956518.

42. Nicklas BJ, You T, Pahor M. Behavioural treatments for chronic systemic inflammation: effects of dietary weight loss and exercise training. Can Med Assoc J. 2005;172(9): 1199-1209; doi: 10.1503/cmaj.1040769.

43. Key T, Appleby P, Barnes I, Reeves G, Endogenous Hormones and Breast Cancer Collaborative Group. Endogenous sex hormones and breast cancer in postmenopausal women: reanalysis of nine prospective studies. J Natl Cancer Inst. 2002;94(8):606-616; doi: 10.1093/ jnci/94.8.606.

44. Eliassen AH, Missmer SA, Tworoger SS, Hankinson SE. Endogenous steroid hormone concentrations and risk of breast cancer: does the association vary by a woman's predicted breast cancer risk? J Clin Oncol. 2006;24(12): 1823-1830; doi: 10.1200/JCO.2005.03.7432.

45. Jethon Z, Murawska-Ciałowicz E. The value of physical activity in cancer prevention [in Polish]. In: MurawskaCiałowicz E, Zatoń M (eds.), The importance of physical activity for health [in Polish]. Wrocław: AWF; 2005; 155-176.

46. Bernstein L. Exercise and breast cancer prevention. Curr Oncol Rep. 2009;11(6):490-496; doi: 10.1007/s11912009-0066-7.

47. Campbell KL, McTiernan A. Exercise and biomarkers for cancer prevention studies. J Nutr. 2007;137(1 Suppl.): 161S-169S; doi: 10.1093/jn/137.1.161S.

48. Friedenreich CM. Physical activity and breast cancer: review of the epidemiologic evidence and biologic mechanisms. Recent Results Cancer Res. 2011;188:125-139; doi: 10.1007/978-3-642-10858-7_11. 
49. Cleary MP, Grossmann ME. Minireview: obesity and breast cancer: the estrogen connection. Endocrinology. 2009;150(6):2537-2542; doi: 10.1210/en.2009-0070.

50. Cleary MP. Impact of obesity on development and progression of mammary tumors in preclinical models of breast cancer. J Mammary Gland Biol Neoplasia. 2013; 18(3-4):333-343; doi: 10.1007/s10911-013-9300-x.

51. Kaaks R, Rinaldi S, Key TJ, Berrino F, Peeters PHM, Biessy $C$, et al. Postmenopausal serum androgens, oestrogens and breast cancer risk: the European prospective investigation into cancer and nutrition. Endocr Relat Cancer. 2005;12(4):1071-1082; doi: 10.1677/erc. 1.01038.

52. Malczyk E, Majkrzak Ż. Selected elements of lifestyle and risk of breast cancer [in Polish]. Probl Hig Epidemiol. 2014;95(4):827-830.

53. Grodecka-Gazdecka S. Association between obesity and breast cancer [in Polish]. Forum Zab Metab. 2011; 2(4):231-238.

54. Playdon MC, Bracken MB, Sanft TB, Ligibel JA, Harrigan M, Irwin ML. Weight gain after breast cancer diagnosis and all-cause mortality: systematic review and meta-analysis. J Natl Cancer Inst. 2015;107(12):djv275; doi: 10.1093/jnci/djv275.

55. Rosato V, Bosetti C, Talamini R, Levi F, Montella M, Giacosa A, et al. Metabolic syndrome and the risk of breast cancer in postmenopausal women. Ann Oncol. 2011;22(12):2687-2692; doi: 10.1093/annonc/mdr025.

56. Vona-Davis L, Howard-McNatt M, Rose DP. Adiposity, type 2 diabetes and the metabolic syndrome in breast cancer. Obes Rev. 2007;8(5):395-408; doi: 10.1111/ j.1467-789X.2007.00396.x.

57. Larsson SC, Mantzoros CS, Wolk A. Diabetes mellitus and risk of breast cancer: a meta-analysis. Int $\mathrm{J}$ Cancer. 2007;121(4):856-862; doi: 10.1002/ijc.22717.

58. Zhu Z, Jiang W, Sells JL, Neil ES, McGinley JN, Thompson HJ. Effect of nonmotorized wheel running on mammary carcinogenesis: circulating biomarkers, cellular processes, and molecular mechanisms in rats. Cancer Epidemiol Biomarkers Prev. 2008;17(8):1920-1929; doi: 10.1158/1055-9965.EPI-08-0175.

59. World Cancer Research Found, American Institute for Cancer Research. Food, nutrition, physical activity, and the prevention of cancer: a global perspective. Washington: American Institute for Cancer Research; 2007.

60. Xia H, Ma S, Wang S, Sun G. Meta-analysis of saturated fatty acid intake and breast cancer risk. Medicine. 2015; 94(52):e2391; doi: 10.1097/MD.0000000000002391.

61. Fritsche KL. The science of fatty acids and inflammation. Adv Nutr. 2015;6(3):293S-301S; doi: 10.3945/an.114. 006940.

62. Bakker MF, Peeters PHM, Klaasen VM, Bueno-de-Mesquita HB, Jansen EHJM, Ros MM, et al. Plasma carotenoids, vitamin $\mathrm{C}$, tocopherols, and retinol and the risk of breast cancer in the European Prospective Investigation into Cancer and Nutrition cohort. Am J Clin Nutr. 2016;103(2):454-464; doi: 10.3945/ajcn.114.101659.

63. Zbucka M, Leśniewska M, Knapp P, Wołczyński S. How we can modify the risk of breast cancer? [in Polish]. Prz Menopauz. 2005;4(6):70-75.

64. Zhang M, Holman CDJ. Low-to-moderate alcohol intake and breast cancer risk in Chinese women. $\mathrm{Br} \mathrm{J}$ Cancer. 2011;105(7):1089-1095; doi: 10.1038/bjc.2011.302.

65. Narod SA. Alcohol and risk of breast cancer. JAMA. 2011;306(17):1920-1921; doi:10.1001/jama.2011.1589. 